\title{
Identifying the Intellectual Virtues in a Demon World
}

\author{
M. C. Young \\ Department of Philosophy, Lakehead University, Orillia Campus, Orillia, Canada \\ Email: m.christopher.young@gmail.com \\ Received July $4^{\text {th }}$, 2012; revised August $9^{\text {th }}$, 2012; accepted August $19^{\text {th }}, 2012$
}

\begin{abstract}
Within contemporary epistemology, notions of intellectual virtue have come to fulfill a prominent role in attempts to provide an account of knowledge. Notions of such virtue can vary, and one particular aspect of this variance concerns how to construe the relationship between the intellectual virtues and particular epistemic ends. The goal of this article is to defend an instrumental connection between the intellectual virtues and the epistemic end of true belief. One type of skeptical argument that attempts to sever this connection, a Cartesian Demon argument, is considered. This Cartesian Demon argument will be summarized, as well as three responses to it. The claim that truth-conduciveness is a tenable criterion for identifying the intellectual virtues is then defended. It is acknowledged that the possibility of a Cartesian Demon does initiate scepticism, but that this scepticism is directed toward identifying specific intellectual virtues and not toward the instrumental connection between intellectual virtue and true belief.
\end{abstract}

Keywords: Intellectual Virtue; Cartesian Demon; Subjective Justification; Truth-Conduciveness

\section{Introduction}

The goal of this article is to defend an instrumental connection between intellectual virtue and true belief; specifically against a Cartesian Demon skeptical argument. This position is formulated not simply as a reaction to the former skeptical argument, but also in response to three other positions offered by James Montmarquet, Jonthan Kvanvig and Casey Swank. Although all three of these authors offer slightly different positions, they all agree that the possibility of a Cartesian Demon initiates doubt about the truth-conduciveness of the intellectual virtues. It is argued that the possibility of a Cartesian Demon does initiate skeptical doubt, but that this doubt is not directed toward the instrumental connection between intellectual virtue and true belief. Rather, this doubt is directed toward those intellectual virtues on our current list of virtues and not toward the connection between intellectual virtue and true belief.

\section{Intellectual Virtues, Cartesian Demons and Normal Worlds}

There are two notions of intellectual virtue that are the focus of contemporary virtue epistemologists; one advocated by virtue reliabilists and another advocated by virtue responsibilists (Axtell, 1997; Greco, 2000). According to virtue reliabilism an intellectual virtue is any aspect of first-nature, or capacities and faculties we are born with, that reliably produces true belief (Axtell, 1996; Axtell, 1998; Bloomfield, 2000). Consequently, virtue reliabilists advocate an instrumental connection between intellectual virtue and true belief, since they count as intellectual virtues capacities and faculties that fulfill a causal role in the maximization of true beliefs, and minimization of false beliefs. Examples of intellectual virtues identified by the virtue reliabilist include: sight, hearing, memory, introspection, deductive and inductive reasoning, and rational intuition (Sosa, 1985; Greco, 1992; Fairweather, 2001). The virtue responsibilist's notion of such virtue differs significantly from the pre- vious notion. This is because the virtue responsibilist advocates a character-based notion of intellectual virtue. Virtue responsebilists therefore focus on aspects of second-nature, or aspects that agents are not born with but can develop or habituate in order to become intellectually virtuous. This is why the position earns the nomenclature "responsibilist", because it focuses on aspects of character that agents can be responsible for developing or habituation. Their list of intellectual virtues includes various character traits, as opposed to capacities and faculties, such as intellectual courage, intellectual humility, intellectual integrity, curiosity, intellectual caution and diligence in intellectual matters (Montmarquet, 1993; Zagzebski, 1996).

Debate between these two camps of virtue epistemologists concerning how the intellectual virtues should be construed is typically focused around attempts to explain, descriptively and prescriptively, epistemological terms. That is, virtue reliabilists and virtue responsibilists often criticize one another's notions of intellectual virtue on the grounds that either cannot adequately account for notions such as justification or knowledge (Axtell, 1997; Greco, 2000; Reed, 2001; Fairweather, 2001). The focus of this article is not to enter into the debate between virtue reliabilists and responsibilists, but instead to focus one particular type of argument that attempts to sever an instrumental connection between intellectual virtue and true belief. As mentioned, the type of argument in question is a Cartesian Demon argument. Virtue reliabilists do advocate an instrumental connection between various intellectual virtues and the epistemic end of true belief, so it would seem that if the argument in this paper is successful it would favour the virtue reliabilist position. This is not so, since one could also construe the intellectual virtues as understood by the virtue responsibilist as possessing an instrumental connection to true belief (Zagzebski, 1996). So neither notion of intellectual virtue is favored, as the focus is solely on maintaining an instrumental connection between intellectual virtue and true belief by responding to a Cartesian Demon argument. Let us now consider this argument.

The Cartesian Demon argument against an instrumental con- 
nection between specific intellectual virtues and true belief begins by proposing that it is possible that our world is a demon world. If our world is a demon world then it is possible for us to hold certain traits, skills or faculties to be truth-conducive, and therefore intellectual virtues, while in fact we are deceived by a malicious Cartesian Demon. The Demon manipulates us into believing various traits, faculties and skills are conducive to true beliefs while in fact they are not conducive to such beliefs. Our beliefs concerning the truth-conduciveness of various intellectual virtues are therefore false. Even further, it could be the case that the traits, skills and faculties we identify as truthconducive could be in fact conducive to false beliefs while those we identify as conducive to false beliefs are conducive to true beliefs. If we relied on "truth-conduciveness" as our criterion for identifying specific intellectual virtues, then our intellectual virtues would actually be intellectual vices and our intellectual vices would be intellectual virtues (Goldman, 1986; Montmarquet, 1987; Kvanvig, 1992; Swank, 2000). Some authors have even proposed the Demon's deception could be so effective that it is undetectable. We cannot detect this deception, for no matter how conclusive our evidence seems to be concerning the truth-conduciveness of certain traits, skills and faculties it is always possible that the evidence, or our beliefs concerning this evidence, has been manipulated by the demon. The mere possibility of the demon impacts our claims about the truth-conduciveness of the intellectual virtues simply because if such a demon existed we would not be able to detect his influence. The demon would manipulate our beliefs at every turn, so that we believe we are obtaining true beliefs, by whatever methods, and yet this is not the case. Hence, the mere possibility of a Cartesian Demon presents a problem for anyone who wants to maintain that there is an instrumental connection between the intellectual virtues and true belief. For it seems that any claim concerning the truth-conduciveness of specific intellectual virtues could be the result of the undetectable manipulations of a Cartesian Demon (Axtell, 2001; Lehrer, 2001).

One possible response to the problem that a Cartesian Demon presents to identifying the truth-conducive properties of agents is to make the distinction between the demon world and "normal" worlds. This is the approach taken by Alvin Goldman. When considering the possibility of a Cartesian Demon systematically misleading agents in regard to the reliability of certain cognitive processes leading to true beliefs, Goldman responds by proposing that we identify truth-conducive traits against the backdrop of normal worlds. That is, the reliability of cognitive processes in producing true beliefs is determined in normal worlds as opposed to demon worlds, where a normal world is identified through the criteria of "a large set of common beliefs about the actual world” (Goldman, 1986). Such a response does not deny that our world could be a demon world, but instead holds that demons are not part of normal worlds and therefore will not impact our ability to identify various truthconducive properties of agents (Goldman, 1986). If we rely on such a response to the Cartesian Demon problem, we can confidently identify certain traits as intellectual virtues by proposing that certain traits are truth-conducive in the normal world, and that this normal world is itself identified by shared beliefs concerning the actual world.

As part of his of his exposition of the Cartesian Demon problem Jonathan Kvanvig begins by considering Goldman's normal worlds response. One significant problem he identifies with this response is the question of whose beliefs will be relied on to determine the parameters of the normal world? According to Goldman the normal world is determined by a set of common beliefs we share about the actual world. Kvanvig asks who exactly is this "we" that is relied on to generate a list of beliefs about the actual world, and therefore normal worlds? Is it meant to include every human agent that has ever existed, only agents from twentieth century western culture, or only a subset of the latter group? As Kvanvig points out, "the set of normal worlds will be different depending on which group one appeals to in defining the notion of a normal world"(Kvanvig, 1992). If we consult some agents' beliefs concerning the normal world we may be surprised that demons fulfill a significant role in their world. Consequently, if we want to rule out the possibility of demons existing and exerting their influence on us in normal worlds we will have to find a way to exclude the beliefs of such agents. Further work would have to be done to designate which normal world beliefs are legitimate and which are not, or to designate whose beliefs we will rely on to identify the normal world and whose beliefs can be legitimately dismissed. Taking such an approach appears to entail a lot more work than merely dealing with the demon directly, as it would likely be very difficult to establish whose beliefs are legitimate so we could then determine the parameters of the normal world. In fact, it would seem that one would have to have a set of uncontroversial epistemological norms already in place in order to dismiss some beliefs while leaning on others to identify the normal world. Such an approach therefore seems to beg the question, for it assumes that we already possess the uncontroversial epistemological norms that would allow us to identify the normal demon free world. Goldman's normal world approach appears to entail as many problems as the original Cartesian Demon problem, if not more, and therefore cannot be relied on as a solution to the latter problem. With this in mind we will now turn to other possible responses to the Cartesian Demon problem for identifying the intellectual virtues.

\section{Epistemic Desires and Subjective Justification}

To reestablish the connection between intellectual virtue and true belief, while acknowledging the possibility of a Cartesian Demon, is the goal of the next section. Before an attempt is made to reestablish such a connection three other responses to the demon problem, offered by Casey Swank, James Montmarquet and Jonathan Kvanvig, are considered. None of these philosophers attempt to reestablish the connection between intellectual virtue and truth-conduciveness, but instead each holds that due to the possibility of a Cartesian Demon we have to reformulate the means by which we either individuate or understand the intellectual virtues. In order to defend the instrumental connection between intellectual virtue and true belief these positions therefore must be addressed. We will begin by considering Swank's position.

Swank accepts the possibility of a Cartesian Demon on the grounds that our world could be a demon world. He proposes that we have to account for why certain traits are considered virtues and others vices based on the qualities such traits possess in the actual world. The actual world might be a demon world, and therefore we cannot designate intellectual virtues to be such on the grounds that they are truth-conducive. Even though we cannot rely on this criterion for individuating the intellectual virtues we nonetheless can identify the various aspects of intellectual character. We simply know, Swank sug- 
gests, that character traits such as open-mindedness, intellectual courage and reasonableness are intellectual virtues while being dogmatic, unreasonable and intolerant of others' beliefs are intellectual vices regardless of any malicious influence of a Cartesian Demon. We know this because we value the former virtues, and would want to possess them, regardless of their connection to truth, and it is the same for the intellectual vices. Even if we found out that being unreasonable and dogmatic were both conducive to true beliefs we would still reject them as vicious and therefore undesirable. Our designation of them as intellectual vices would be based solely on the fact that they are just plain bad character traits to have. They simply represent defects in character and for this reason are considered vicious or vices. Intellectual virtues, on the other hand, represent character traits we deem desirable and are therefore considered virtuous solely on that basis. Our identification of intellectual virtues as such, and intellectual vices as such, has nothing to do with their connection to truth and falsity, but instead occurs simply due to perceiving them as good and bad character traits (Swank, 2000).

There are at least two problems with Swank's response to the evil demon problem. First, the claim that we would value those character traits typically designated intellectual virtues regardless of their connection to truth seems presumptuous. Swank's argument relies on an appeal to what his audience values. He proposes that even if the demon let us in on his secret by telling us that what we have identified as intellectual virtues are in fact conducive to false beliefs, while intellectual vices are conducive to true beliefs, we would still want to possess those character traits deemed intellectual virtues and discard all concern for true belief due our aversion to the standard list of intellecttual vices (Swank, 2000). Such a claim assumes that Swank's audience shares either his intuitions or value set. There is no guarantee, though, that any agent who was confronted with the situation as Swank presents it would judge it as he does. When confronted with the possibility that what we typically think of as intellectual virtues are not truth-conducive, but in fact conducive to false beliefs, there is no guarantee that one would discard all concern for the truth; specifically that its value is easily overridden by the value of those intellectual virtues on the standard list. One can easily imagine someone responding that the value of truth outweighs the value of those character traits typically deemed intellectual virtues, and therefore it is the former that must be valued as opposed to the latter. Second, Swank also assumes that the demon's influence is limited to beliefs concerning whether the intellectual virtues are truthconducive, and that we are not deceived in regard to our value judgments concerning those virtues. If our world is one where we could be deceived by a Cartesian Demon concerning the truth-conduciveness of certain character traits, then it could also be a world where such a Demon deceives us concerning what is valuable. Swank therefore cannot rely on our beliefs concerning the value of certain traditionally understood intellectual virtues, and the disvalue of certain traditionally understood intellectual vices, for our beliefs in these respects could also be wrong due to the influence of a malicious demon. Consequently, by not dealing with the demon directly Swank has not been able to display the value of the intellectual virtues, since the demon could be deceiving us in this regard also.

Turning to Montmarquet and in response to the possibility of a Cartesian Demon, he proposes that we have to reformulate the individuating characteristic of the intellectual virtues. Since it is possible that the Cartesian Demon exists, and deceives us into believing that certain traits are truth-conducive while such traits are conducive to false beliefs, we cannot hold "truth-conduciveness" to be the defining characteristic of the intellectual virtues. Instead, he suggests, the definitive characteristic of the intellectual virtues is that they are desired by the epistemically responsible agent. That is, the intellectual virtues are held to be traits that any agent who desires the truth would want to have. They are desired by the epistemically responsible agent, since such an agent is epistemically conscientious and therefore tries her best to obtain true beliefs and avoid false beliefs. Such a desire therefore leads the epistemically responsible agent to habituate those character traits deemed intellectual virtues. Presumably, then, their desirability is premised on the fact that they appear to the epistemically responsible agent to be truthconducive, but since their truth-conduciveness cannot be assured, due to the possibility of systematic deception by a Cartesian Demon, the most that we can say is that they are desirable. Hence, it is acknowledged that intellectually virtuous character traits appear to be truth-conducive, but since the agent's beliefs concerning such traits are possibly influenced by a malevolent demon it cannot be asserted that the intellectual virtues are in fact truth-conducive. At most, one can only say that they are desirable for any agent concerned with epistemic ends (Montmarquet, 1987; Montmarquet, 1993; Montmarquet, 2000).

In reaction to the possibility that we are systematically deceived by a Cartesian Demon into believing that the intellectual virtues are truth-conducive, when in fact they are not, Kvanvig proposes we must instead construe the intellectual virtues as conducive to subjective justification. He claims that if it were the case that a demon was powerful enough to ensure that some agent's beliefs always came out false, despite that agent's best efforts and intellectual character, we could not hold that such an agent possessed any dispositions toward true beliefs. This agent could not be held to have any dispositions toward true beliefs, since nothing that the agent attempts, or is disposed to do, could ever lead him to have true beliefs. Kvanvig admits that it is unlikely that a Cartesian Demon exists, and that there are decisive philosophical objections to its very possibility, but nonetheless he holds that it is a useful heuristic device that demonstrates a significant point. The significant point is that to obtain and sustain true beliefs agents require a cooperative environment. An agent could be completely intellectually virtuous, but if her environment is not cooperative in enabling her to obtain true beliefs, as is the case with the demon world, then her virtuous character will not facilitate this end. It is possible, then, that our world is like the demon world, such that it is uncooperative in enabling agents to obtain true beliefs no matter their personal level of virtue (Kvanvig, 1992).

Due to the impact of the possibility of uncooperative environments on the truth-conducive construal of the intellectual virtues Kvanvig suggests, as mentioned, that we understand such virtues as conducive to subjective justification. His first step toward this conclusion is to propose that even though we cannot construe the intellectually virtuous agent as disposed to obtaining true beliefs we can construe such an agent as disposed to trying to obtain true beliefs. The agent is unsuccessful, given the environment she lives in, but nonetheless she attempts to obtain true beliefs through the influence of her virtuous character. She employs means that appear to her to be truth-conducive, by becoming intellectually virtuous, and therefore can be described as trying her best to obtain true beliefs 
and avoid false beliefs. Kvanvig then suggests that a natural way to construe the possession of justified beliefs for agents is to hold that such possession occurs when the agent tries her best to obtain true beliefs and avoid false beliefs. That is, if an agent wants to obtain only true beliefs, and this leads her to adopt the best methods to this end, and, in turn, to be careful in regard to the reasons for which she accepts a belief, then we can describe the belief she settles on to be justified even if it is not true. The intellectual virtues would therefore be understood as conducive to justified beliefs, as opposed to true beliefs, since they would be the means that agents employ in the attempt to obtain true beliefs. Kvanvig admits that this would only lead the agent to be subjectively justified in holding the beliefs she has, since from an objective point of view her beliefs are false and therefore are unjustified, but nonetheless the agent tries her best from her own perspective and is therefore subjectively justified in believing as she does (Kvanvig, 1992).

\section{Intellectual Virtue in a Demon World}

In this section the goal is respond to the Cartesian Demon problem in order to maintain truth-conduciveness as the individuating characteristic of the intellectual virtues. It is argued that what the possibility of a Cartesian Demon initiates doubt about is not the connection between intellectual virtue and true belief, but rather those virtues on the standard list of intellectual virtues. More specifically, that when faced with the possibility of a Cartesian Demon we do not have to conclude that the intellectual virtues are not truth-conducive, but instead that we could be simply wrong concerning those traits we have identified as intellectual virtues. An attempt is therefore made to maintain the truth-conducive criterion for determining which traits are intellectual virtues, and, in turn, propose that it would be more warranted to doubt that those traits we have identified as intellectual virtues are actually intellectual virtues given the presence of a Cartesian Demon.

Linda Zagzebski was the first to suggest that what is brought into to doubt by the possibility of a Cartesian Demon are those traits on the standard list of intellectual virtues, as opposed to the connection between intellectual virtue and true belief. When confronted with the Cartesian Demon argument it was her claim that the connection between intellectual virtue and true belief can be maintained. Assuredly, the possibility of systematic deception by a Cartesian Demon will generate scepticism, but it need not be scepticism concerning whether an intellectual virtue must be truth-conducive to be considered an intellectual virtue. The latter claim need not follow, since one could simply insist that for a trait, skill or faculty to be considered an intellectual virtue it must be truth-conducive. If one insists that "truth-conduciveness" is the definitive characteristic of an intellectual virtue, then when confronted by a Cartesian Demon one would propose that we were simply wrong concerning what we identified as intellectual virtues because none of the former were in fact truth-conducive. The Cartesian Demon misleads us because we believe that we are intellectually virtuous, and are therefore acquiring true beliefs through various intellectual virtues, while in fact this is not the case. Either the demon implants false beliefs in us concerning which dispositions are truth-conducive or he manipulates the environment in such a way that none of our dispositions facilitate true beliefs. In such a world no traits are truth-conducive. This position mirrors the positions of Montmarquet and Kvanvig, for it agrees that no traits would be truth-conducive in such a world, but instead concludes from this that such a world would be devoid of intellectual virtue. We would therefore not have to re-conceptualize those traits, faculties and skills that were identified as intellectual virtues, along the lines suggested by Montmarquet and Kvanvig, but instead could maintain the "truth-conducive" conceptualization and simply exercise doubt in regard to our present list of intellectual virtues (Zagzebski, 1996; Zagzebski, 2000).

Thus, Zagzebski offers an alternative object for doubt in response to the possibility of a Cartesian Demon. Her proposal is that when faced with such a demon we could maintain our standard list of intellectual virtues, and doubt the criterion of truth-conduciveness, or we can maintain the criterion of truthconduciveness and doubt those traits on the standard list. The key point of contention that must be resolved in order to choose between these two alternatives is whether to insist on maintaining the standard list and then alter our criterion of intellectual virtue, or insist on the criterion of intellectual virtue and then alter our standard list. In what follows two reasons will be offered for why it is more warranted to insist on the criterion of truth-conduciveness, and then alter our standard list, than to insist on the standard list and alter the criterion of intellectual virtue.

To insist on the truth-conducive criterion, as opposed to the standard list, appears to be the more warranted position that follows from the Cartesian Demon possibility, first, because both Montmarquet and Kvanvig still rely on the notion of truthconduciveness when offering their respective positions. Beginning with Montmarquet's position recall that he suggests that the definitive characteristic of the intellectual virtues is that they are desired by any agent who desires the truth. When confronted with this criterion it seems reasonable to ask why the intellectual virtues are considered desirable by such an agent? Montmarquet's answer is to propose that they are desired by the agent who desires truth because such an agent is epistemically conscientious and therefore tries her best to obtain true beliefs and avoid false beliefs. Various character traits are deemed truth-conducive by such an agent, and are therefore habituated due the agent's general desire to obtain truths and avoid falsehoods. The desirability of these various traits are therefore dependent on the fact that they appear to be truth-conducive. The criterion of truth-conduciveness is therefore still maintained with Montmarquet's position, for it is through this criterion that the epistemically responsible agent identifies various intellecttual virtues, deems them desirable, and, in turn, attempts to form beliefs through their influence.

A similar conclusion emerges from consideration of Kvanvig's position. Recall that he proposes we can construe the intellectual virtues as conducive to subjective justification since agents employ these virtues in order to try to obtain true beliefs and avoid false beliefs. The agent is subjectively justified in holding the beliefs she does because she has done her best to aim at the truth, while avoiding the false, by adopting various traits, skills and faculties that appear to her to be conducive to these ends. The agent therefore employs means that appear to be truth-conducive, by becoming intellectually virtuous, and can, in turn, be described as trying her best to obtain true beliefs and avoid false beliefs. Consequently, the ascription of "subjective justification" arises only because the agent has employed mechanisms for belief formation that appear to her to be truthconducive. 
Thus, with each position the "truth-conducive" criterion is maintained. The intellectual virtues are deemed desirable because they appear to be truth-conducive, and they confer subjective justification because the agent has adopted the intellectual virtues with the belief that they will help her to obtain truths and avoid falsehoods. If the former judgments presuppose judgments concerning the truth-conduciveness of such traits, then this gives us a reason for maintaining the truthconducive criterion. For judgments concerning the desirability and justification-conduciveness of the intellectual virtues for agents in the demon world presuppose judgments concerning their ability to be truth-conducive. It is the appearance of the truth-conduciveness of the intellectual virtues that fulfills a crucial step in getting to the claims that agents have done something epistemically desirable or that they are subjectively justified. Of course, it is possible to claim that certain traits, skills or faculties are epistemically desirable on grounds other than being truth-conducive, or that some agent is subjectively justified without reference to truth-conducive intellectual virtues. So one does not have to rely on the notion of truth-conduciveness to offer such claims, but this is not what occurs with either of the positions offered by Montmarquet or Kvanvig. Instead, both rely on the perceived truth-conduciveness of the intellectual virtues in order to then establish their respective claims concerning the individuating criterion of such virtues.

Since truth-conduciveness still fulfills this role in the attempt to offer other criterion for the intellectual virtues one can maintain the truth-conducive criterion of the intellectual virtues. In such a situation one could claim that agents in the demon world identify the intellectual virtues on the grounds that they appear truth-conducive, but nonetheless these agents are wrong because of the manipulations of a Cartesian Demon. Consequently, their list of intellectual virtues is incorrect, but they nonetheless have done something epistemically desirable, or are subjectively justified in what they believe, because such agents have attempted to employ traits, skills or faculties that appeared to them to be truth-conducive. So the possibility of a Cartesian Demon does not inevitably lead to the claim that we have to alter the individuating criterion of the intellectual virtues, since both Montmarquet and Kvanvig acknowledge that agents in a demon world would still identify certain traits, faculties or capacities as intellectual virtues on the grounds of their being truth-conducive. Upon discovering a Cartesian Demon we would then say that they were wrong, but nonetheless subjectively justified in what they believe or that they did something epistemically desirable because they were concerned with true belief. Nonetheless, the criterion relied on by demon world residents to identify the intellectual virtues would still be truthconduciveness.

The second reason why the truth-conducive criterion should be maintained, and the standard list doubted, which is built upon the first, is that we are all in the same position as the agents in the demon world thought experiment. The judgments of agents in the demon world are made from the oblique position. That is, such agents exist in an unprivileged position where they are unaware that they are being systematically deceived by a Cartesian Demon. Montmarquet's and Kvanvig's reformulated positions suggest that it is appropriate for these agents to identify the intellectual virtues on the basis of their being truth-conducive, because these agents exist in the oblique position. We too, though, are in the same oblique position. That is, we exist in an unprivileged position where we do not know, or are unaware, whether we are being systematically deceived by a Cartesian Demon. So if it is reasonable for the agents in the demon world scenario to still judge intellectual virtues to be such on the basis of their being truth-conducive, because they exist in the oblique position, then it would be reasonable for us to do the same. Neither Montmarquet nor Kvanvig, nor anyone else, claims that it is true that there is such a demon, that we can be certain that such a demon exists or that we have discovered such a demon. Instead, such a demon is only a possibility. The demon represents, as Kvanvig puts it, a useful heuristic device to convey the point that the world might be other than how it appears to us and is not always cooperative in helping us obtain and sustain true beliefs (Kvanvig, 1992). Since we do not know whether such a demon exists, and it represents only a possibility, we are in the same oblique position as the agents in the thought experiments upon which Montmarquet and Kvanvig build their reformulated positions. That is, we all exist in the unprivileged position of not being able to determine whether the demon exists or not. Since we all exist in this oblique position we can make judgments based on how things appear, as do the agents in both Montmarquet's and Kvanvig's reformulated positions. Consequently, when we formulate our criterion from the oblique position we will identify intellectual virtues on the basis of their truth-conduciveness (Kvanvig, 1992; Montmarquet, 2000). Again, if we discovered that there is such a demon we may say something different about what occurred when we employed traits, skills and faculties that appeared truth-conducive. We may say that we were doing something epistemically desirable, or that we were subjectively justified, but it would still be the case that we identified various traits, skills and faculties as intellectual virtues on the grounds of their truth-conduciveness. Hence, the truth-conducive criterion for individuating the intellectual virtues is still maintained.

The conclusion that then emerges is that we can maintain the truth-conducive criterion for the intellectual virtues, and propose that if the demon exists we are simply wrong concerning those traits on the standard list. We exist in the oblique position so we assess traits, skills and faculties based on how they appear to us, as do the agents in Montmarquet's and Kvanvig's reformulated positions. The possibility of the demon still generates scepticism, but this scepticism is now directed at the virtues on the standard list. That is, since we are aware of the possibility of a Cartesian Demon systematically deceiving us we must exercise some doubt, or scepticism, somewhere. This doubt is directed toward those virtues on the standard list as opposed to the claim that the individuating characteristic of the intellectual virtues is truth-conduciveness. This does not entail that we can never identify specific traits, skills or faculties as intellectual virtues, since certain traits will always appear to us to be truth-conducive, but simply that there is always a possibility that we could be wrong concerning those virtues currently on the list. The possibility of a Cartesian Demon causes us to formulate our claims concerning the intellectual virtues cautiously. Kvanvig and Montmarquet offer cautious formulations, and the cautious formulation offered here, following Zagzebski, is to hold that we could be wrong concerning those virtues on the list.

\section{Doubts Concerning Doubting the Standard List}

It should be noted that both Montmarquet and Kvanvig consider the possible response that we are simply wrong concern- 
ing those virtues on the standard list, and both reject this possibility. In order to maintain that truth-conduciveness should be the means by which we understand the intellectual virtues their reasons for rejecting this possibility must be addressed.

Beginning with Montmarquet, he rejects the response that we are simply wrong concerning those traits on the standard list on the grounds that it would sever connections between being virtuous and being praised and being vicious and being blamed. That is, he proposes that if we took the approach that we were simply wrong concerning those virtues on the standard list, and the roles of virtues and vices were reversed, then we would have to, in turn, reverse our judgments of praise and blame: blaming agents for possessing virtues now deemed vices, and praising agents for vices now deemed virtues. Montmarquet proposes that it would be inappropriate to reverse our judgments of agents in this way, but this is what would occur if we attempted to maintain the position that we were simply wrong concerning those virtues on the standard list (Montmarquet, 2000).

In response it seems reasonable to suggest that even if we reversed our judgments concerning what are vices and virtues we would not reverse our judgments concerning praise and blame. That we would not reverse such judgments is what we would expect given other aspects of the virtue perspective. Judgments concerning praise and blame within the virtue perspective are dependent upon the impetuses for action, i.e. the virtues. Consequently, virtue ethics has been often described as input driven as opposed to output driven (Garcia, 2003). There is no reference to consequences, or a particular output, in the assessment of actions within virtue ethics, but instead only to particular inputs; or the virtuous traits of the relevant actors. This is why, for the virtue ethicist, character is essential for determining what is morally right or wrong, good or bad, and the appraisal of action is derived from the appraisal of character (Oakley, 1996). Thus, agents in the demon world still would be praised for their virtuous effort; or the attempt to adopt motivations they perceived to be truth-conducive in order to guide their behaviour. We would therefore not alter our judgments concerning praise and blame in regard to such agents, since they were attempting to be virtuous and, according to their best judgments, acting through the influence of virtuous dispositions.

Turning to Kvanvig, he objects to the claim that what the Cartesian Demon brings into doubt are the virtues on the standard list by proposing, first, that this position would entail that the inhabitants of the demon world possess no intellectual virtues. This cannot be the case, he suggests, since those traits identified as intellectual virtues by demon-world residents still would be considered admirable, and therefore they must still be virtues (Kvanvig, 1992). The problem with this argument is that Kvanvig assumes, similar to Swank, that the demon's influence is limited to judgments concerning whether the intellectual virtues are truth-conducive, and that such a malicious agent would not deceive us concerning our value judgments. But, if our world is a demon-world where we could be deceived concerning the truth-conduciveness of certain traits, skills and faculties, then it could also be a world where we could be deceived concerning what is admirable and not admirable. If this is the case, then the criterion of being admirable is just as susceptible to doubt, and is equally unhelpful, for identifying the intellectual virtues as is the criterion of truth-conduciveness. Consequently, we cannot rely on the criterion of being admirable to claim that there are still intellectual virtues in the demon-world in order to then reject the possibility that we are simply wrong concerning those traits on the standard list.

What is more threatening to the position advocated in this paper, though, is Kvanvig's first premise in the former argument; i.e. that claiming the standard list is wrong would entail that inhabitants of the demon-world possess no intellectual virtues. Since it has been proposed that the demon possibility leads to doubt concerning those traits on the standard list it would seem that one must also concede that no intellectual virtues exist in such a world; i.e. our world. To put the point another way, since the possibility of a Cartesian Demon leads us to doubt the intellectual virtues on the standard list, and this situation is similar to the restrictions induced by uncooperative environments, it would seem that one would have to concede that in our world there are no intellectual virtues. This latter claim, though, does not have to be conceded, for, as previously argued, we do not know whether such a demon exists, or the extent to which our environment misleads us into believing that certain traits are truth-conducive when in fact they are not. We are in the oblique position in regard to both, and perceive certain traits, skills and faculties to be truth-conducive, and thus, as far as we can tell, there are intellectual virtues; i.e. traits, skills and faculties that are identified as intellectual virtues because they are truth-conducive. If we discovered that a demon was deceiving us, or that aspects of our environment misled us into believing that certain traits were intellectual virtues when in fact they are not such, then we would have to concede either that there are no intellectual virtues in our world or that we have not correctly identified any such virtues yet. Since we are in the oblique position, and have not made any such discovery, we can conclude that our world does contain intellectual virtues for we have been able to identify various traits, skills and faculties as truth-conducive. Consequently, Kvanvig's claim that doubting the standard list, due to the possibility of systematic deception, would lead to the conclusion that there are no intellectual virtues in our world is unwarranted.

\section{Conclusion}

The main concern of this article was whether the possibility of a Cartesian Demon would initiate scepticism concerning truth-conduciveness as the individuating criterion for identifying the intellectual virtues. Arguments offered by Swank, Montmarquet and Kvanvig that proposed that the demon possibility would initiate such scepticism, as well as the replacement criterion each advocated, were considered. It was argued that the demon possibility does initiate scepticism, but that this scepticism can be directed toward our list of virtues as opposed to the criterion of truth-conduciveness. Other possible criteria offered by these authors for identifying the intellectual virtues were found to be either subject to the same doubt that would be directed toward the truth-conducive criterion, given the possibility of a Cartesian Demon, or to be dependent upon the perceived truth-conduciveness of the intellectual virtues in a demon world. When formulating Cartesian Demon thought experiments, agents in the demon world are construed as being in the oblique position concerning the demon's existence, and therefore such agents identify the intellectual virtues based on their perceived truth-conduciveness. Since we are also in the oblique position concerning the existence of the Cartesian Demon it was proposed that we should also act on the perceived 
truth-conduciveness of specific traits, faculties and skills when identifying the intellectual virtues. Consequently, the truthconduciveness criterion is maintained and doubt is instead directed toward our current list of intellectual virtues.

\section{REFERENCES}

Axtell, G. (1996). Epistemic-virtue talk: The reemergence of American axiology? The Journal of Speculative Philosophy, 10, 172-198.

Axtell, G. (1997). Recent work on virtue epistemology. American Philosophical Quarterly, 34, 1-26.

Axtell, G. (1998). The role of the intellectual virtues in the reunification of epistemology. The Monist, 81, 488-508.

Axtell, G. (2001). Epistemic luck in light of the virtues. In A. Fairweather, \& L. Zagzebski (Eds.), Virtue epistemology: Essays on epistemic virtue and responsibility (pp. 158-177). Oxford: Oxford University Press.

Bloomfield, P. (2000). Virtue epistemology and the epistemology of virtue. Philosophy and Phenomenological Research, 60, 23-43. doi:10.2307/2653426

Fairweather, A. (2001). Epistemic motivation. In A. Fair-weather, \& L. Zagzebski (Eds.), Virtue epistemology: Essays on epistemic virtue and responsibility (pp.63-81). Toronto: Oxford University Press.

Garcia, J. L. A. (2003). Practical reason and its virtues. In M. DePaul, \& L. Zagzebski (Eds.), Intellectual virtue: Perspectives from ethics and epistemology (pp. 81-107). Oxford: Clarendon Press.

Goldman, A. I. (1986). Epistemology and cognition. Cambridge, MA: Harvard University Press.

Greco, J. (1992). Virtue epistemology. In J. Dancy, \& E. Sosa (Eds.), A companion to epistemology (pp. 520-522). Cambridge, MA: Basil Blackwell.
Greco, J. (2000). Two kinds of intellectual virtue. Philosophy and Phenomenological Research, 60, 179-184. doi:10.2307/2653438

Kvanvig, J. (1992). The intellectual virtues and the life of the mind: on the place of the virtues in epistemology. Savage: Rowman and Littlefield Publishers, Inc.

Lehrer, K. (2001). The virtue of knowledge. In A. Fairweather, \& L. Zagzebski (Eds.), Virtue epistemology: Essays on epistemic virtue and responsibility (pp. 200-213). Oxford: Oxford University Press.

Montmarquet, J. A. (1987). Epistemic virtue. Mind, 96, 482-497. doi:10.1093/mind/XCVI.384.482

Montmarquet, J. A. (1993). Epistemic virtue and doxastic responsibility. Lanham: Rowman and Littlefield Publishers, Inc.

Montmarquet, J. A. (2000). An "internalist" conception of epistemic virtue. In G. Axtell (Ed.), Knowledge, belief, and character: Readings in virtue epistemology (pp. 135-148). New York: Rowman and Littlefield Publishers Inc.

Oakley, J. (1996). Varieties of virtue ethics. Ratio, 9, 128-152. doi:10.1111/j.1467-9329.1996.tb00101.x

Reed, B. (2001). Epistemic agency and the intellectual virtues. The Southern Journal of Philosophy, 39, 507-526. doi:10.1111/j.2041-6962.2001.tb01831.x

Sosa, E. (1985). Knowledge and intellectual virtue. Monist, 68, 226245.

Swank, C. (2000). Epistemic vice. In G. Axtell (Ed.), Knowledge, belief, and character: Readings in virtue epistemology (pp. 195-204). New York: Rowman and Littlefield Publishers Inc.

Zagzebski, L. (1996). Virtues of the mind: An inquiry into the nature of virtue and the ethical foundations of knowledge. Cambridge: Cambridge University Press.

Zagzebski, L. (2000). Précis of the virtues of the mind. Philosophy and Phenomenological Research, 60, 169-177. doi:10.2307/2653437 